\title{
Perspectivas y polos de desarrollo en América Latina
}

\section{AMERICA LATINA COMO REGION}

También en América Latina, la historia no se mide en décadas, sino en acontecimientos. No obstante ello, las dos décadas desde la revoIución cubana constituyen un motivo para señalar determinados desarrollos y tendencias en toda América Latina. El escape de Cuba del sistema interamericano significa para América Latina, el inicio de una segunda fase de descolonización. Debido a que la mayoría de las naciones de la región han podido conquistar hace mucho tiempo, su independencia política pero no la económica, el escape cubano de la dependencia de EE. vu. indicó el inicio de una nueva era.

De aquella fecha en adelante, América Latina ha sido un continente en crisis. A pesar de los muchos problemas comunes de desarrollo y dependencia, las diversas naciones se han desarrollado en forma muy diferente en los últimos veinte años. La paralelidad de niveles de desarrollo muy desiguales -inclusive dentro de algunas naciones- ya no permite hablar de una tendencia uniforme de desarrollo. Las estructuras económicas y los sistemas políticos en la región son además tan difícilmente comparables porque las naciones en cuestión han sido integrados en el sistema internacional en medida diferente. El crecimiento económico ha traído, para muchos países, nuevas dependencias, particularmente en los casos de los países más pequeños que ya no son dependientes únicamente de las naciones industriales sino también de los polos de desarrollo regionales. Entre estos polos de desarrollo se encuentran indudablemente, México y Brasil, mientras que Venezuela y Argentina, si bien poseen cierto potencial para poder ocupar tal posición, no alcanzan los niveles de influencia de México o de Brasil por razones económicas y/o políticas.

Indudablemente resulta atrevido pretender proyectar hacia el fu-

(Texto revisado de una conferencia dictada el 8 de octubre de 1978, ante el Glub Ibérico en Bonn/R.F.A.) 
turo las tendencias del desarrollo latinoamericano de los últimos veinte años. No obstante, se puede derivar ciertas conclusiones de las conductas internas e internacionales de las naciones: las fluctuaciones del desarrollo de los sistemas económicos y políticos se parecen a ondas que oscilan con frecuencias muy diferentes de nación a nación. La "estabilidad de la inestabilidad" resultante de ellas proporciona ciertas bases para las perspectivas de América Latina en Ios años ochenta.

\section{La posición internacional.}

La mayoría de los paises latinoamericanos pertenece, sin duda, al grupo de Ios que "han Ilegado tarde" en el sistema internacional, particularmente en comparación con aquellos países del mundo que también conquistaron su independencia a principios del siglo xrx. Hasta la Revolución Cubana, los países de América Latina jugaban un papel relativamente insignificante en Ia política internacional y no tiene sentido especular sobre las razones de este hecho. A partir. de 1959, sin embargo, América Latina se ha convertido rápidamente en un factor importante en el escenario de la política mundial. En comparación con otras regiones del mundo, se destaca sobre todo el crecimiento desproporcionado de la influencia de algunos de sus países claves, como los son Brasil, México, Argentina, Venezuela y también Cuba. En Ia misma medida, Latinoamérica se ha convertido en un socio importante dentro de la economía mundial, debido a sus tasas de crecimiento económico respetables dentro del Tercer Mundo, a la transferencia de capital de las naciones industriales y a su riqueza de recursos minerales y agropecuarios.

Su intensiva integración en las relaciones económicas mundiales y su dependencia de las naciones industriales, resultado de la misma, son precisamente los factores que hacen vacilar las posiciones políticas de América Latina entre los países industriales y el Tercer Mundo: Sus élites se autointerpretan sin duda como parte de occidente culturalmente, pero muchos empiezan a convencerse lentamente que sus países son mucho más parecidos estructuralmente a los del Tercer Mundo que a las naciones industriales.

Esta actitud se ha convertido en una especie de ideología en algunas élites, que parece corresponder perfectamente al hecho de que varios países se ven como naciones en ascenso dentro del sistema internacional. En deducción analógica al esquema clasista de la sociedad, 
interpretan la jerarquía internacional como estratificada en los estratos superior, medio e inferior. Las naciones industriales occidentales y Japón representan el estrato superior, las naciones pobres del Tercer Mundo el inferior. Se colocan a ellos mismos -igual que a uná parte de los países socialistas- en la clase media. Basándose en esta autointerpretación, los estados latinoamericanos en cuestión buscan alianzas, según sus intereses, una vez con la clase alta de la jerarquía internacional, otra vez con el "proletariado" internacional -los países pobresen contra del "club de Ios ricos". En esto sus objetivos son claros. Buscan asegurarse económicamente y participar en las decisiones a nivel del sistema internacional. No es posible predecir por el momento, si esta política de alianzas fluctuantes será beneficiosa a la larga.

La emancipación internacional de América Latina ha provocado naturalmente, un creciente distanciamiento de EE. UU. debido a los intereses discrepantes. Al mismo tiempo sin embargo, la región se ha venido orientando más hacia Europa. El interés en la región de otras potencias económicas y políticas ha crecido en la medida en que se han diversificado las relaciones externas de América Latina. Esto es cierto sobre todo, respecto a Europa Occidental y Japón iy en menor escala, a los países socialistas y China. La política de la diversificación hacia afuera caracterizará también en el futuro, la posición de los países latinoamericanos. En este contexto algunos tratan de mantener abiertas todas las opciones. En Brasil y Cuba en particular, seguirán marcando el paso de una polftica exterior latinoamericana no solamente regional, sino mundial. Los dos países se entienden como eslabones entre los diferentes mundos, por distintas razones: Guba se entiende como puente entre el Tercer Mundo y el campo socialista; Brasil -en representación de una gran parte del continente- es como puente entre el Primer y el Tercer Mundo.

América Latina seguirá jugando un papel muy importante en la creación de un nuevo orden económico mundial. Sus crecientes chan. ces đe imponer sus intereses propios permitirán a los países latinoamericanos considerar cada vez menos sus relaciones tradicionales, tanto con EE. UU. como con Europa. Sin embargo, esto se enfrenta al hecho de que muchos países de la región obtienen su peso político internacional justamente y en gran parte, de la estrecha cooperación con dichos países industriales occidentales. Su influencia en el sistema internacional, no obstante, poco dice acerca de su capacidad de superar el subdesarrollo y la dependencia en sus propias casas. 


\section{La cooperación regional.}

A pesar del empeño demostrado durante más que treinta años por la CEPAL, la organización regional de las Naciones Unidas para el desarrollo de América Latina, los intentos integracionistas inspiradas por ella han tenido poco éxito relativamente. Es cierto que las formas de cooperación han cambiado con frecuencia en el curso de los años. La GEPAL partió de la idea de que a nivel regional, resultaría más fácil modernizar las economias nacionales, industrializándose cada país en los sectores de sus mayores ventajas comparativas. La integración regional debía orientarse en el objetivo de crear en América Latina un mercado común, a largo plazo. El Mercado Común Centroamericano (MCCA) y el Area Latinoamericana de Libre Comercio (ALALC), en particular, eran vistos como fases transitorias de un desarrollo orientado a largo plazo, en el ejemplo de la Comunidad Europea. Mientras que en el MCCA se pudieron lograr rápidos mejoramientos intrarregionales del comercio, los esfuerzos realizados dentro del ALALG para coordinar el comercio exterior y las políticas de industrialización no tuvieron éxito en gran parte. Además los países miembros menores pronto se dieron cuenta que los estados ABM (Argentina, Brasil, México) se compartían casi todos Ios beneficios del ALALC debido a su industrialización más avanzada.

Cuando en América Latina se impuso la idea, a finales de los años sesenta, de que la integración regional sólo era posible entre países con un desarrollo aproximadamente similar, se fundó el Pacto Andino. Esta unión aduanera previó la armonización de los programas de desarrollo industrial, la integración de las infraestructuras y también la amplia cooperación financiera de los países miembros (Bolivia, Chile, Ecuador, Colombia, Perú, Venezuela). De la distribución regional de los centros de desarrollo industrial y las restricciones para las inversiones extranjeras, surgió pronto un conflicto político entre los países del Pacto Andino. Las divergencias provocaron la salida de Chile en 1976; de esta fecha en adelante este modelo de integración, a pesar de indudables logros económicos, no ha inspirado más impulso de desarrollo relevantes.

El amplio fracaso de estos intentos de cooperación regional llevó a la tentativa de una nueva forma de cooperación regional con la fundación, en 1975, del Sistema Económico Latinoamericano (SELA). Tanto el ALALC Como el MCGA, habian otorgado prioridad al libre comercio, dejando la extensión de lọs intentos integracionistas a 
cargo de las empresas privadas en su mayoría, transnacionales. Por su parte, el Pacto Andino había intentado acentuar las políticas de desarrollo y el rol del estado en el proceso de integración. El sELA finalmente, fue concebido como instrumento de coordinación para la cooperación económica entre los estados, en base a las experiencias hechas hasta entonces. El Sistema Económico Latinoamericano tiene el doble objetivo de ofrecer mecanismos de integración flexibles hacia adentro y de acumular "poder de negociación" hacia afuera, frente a los paises industriales. Esta nueva forma de cooperación caracteriza la más decidida intervención estatal en las cuestiones de cooperación económica en América Latina. Tal proceso corresponde a la tendencia general en el Tercer Mundo, de acentuar la "conciencia colectiva de sí mismo" ("collective self-reliance").

Debido a nuevas relaciones de poder, la cooperación regional a largo plazo se orientará aún más hacia los nuevos polos de desarrollo regionales en cuyas zonas de influencia se produciría un tipo de integración económica informal. Este proceso indudablemente entraña mayores peligros de conflicto, de modo que no se pueden excluir futuros conflictos regionales sobre los recursos naturales. Por otro Iado, se darán también mejores perspectivas de crecimiento en comparación con los anteriores intentos de cooperación; de ellas se beneficiarían los polos de desarrollo mismos en primera instancia. De modo que la cooperación regional no constribuirá, a largo plazo, a superar las diferencias intrarregionales de desarrollo, sino más bien las acentuará.

\section{Las estructuras económicas.}

A pesar de las considerables tasas de crecimiento en los últimos años -sobre todo de algumos países de América Latina- el progreso económico de la región se limita a pocos sectores. En la mayor parte de los países aún no se ha logrado construir sistemas económicos internos relativamente estables. Su dependencia del capital y la tecnología extranjera ha crecido en la medida en que los países de la región se han dedicado a producir, además de sus productos de exportación tradicionales, bienes destinados al mercado mundial cuya fabricación les obliga a importar bienes de capital y tecnología moderna. Para poder obtener las divisas necesarias, la mayoría de los países latinoamericanos tiene que producir prioritariamente para la exportación, de modo que este tipo de industrialización sólo en muy 
pocos casos responde a las necesidades de las masas populares nacionales.

Así, América Latina hoy en día se presenta como una región semiindustrializada cuya producción industrial ha alcanzado más o menos los niveles de la Comunidad Europea del año 1950. Hasta 1990, América Latina podrá alcanzar el volumen de la producción industrial de Ia CE para 1970. Tal perspectiva sin embargo, no debe llevarnos a suponer que con ello logrará un bienestar similar, ya que la población de América Latina está creciendo al doble ritmo comparado con la ce.

En el futuro, el ya desequilibrado desarrollo regional y social se acentuará aún más, porque los polos de desarrollo sobre todo buscarán concentrar en ellos Ios recursos regionales e internacionales. Además, la necesidad de superar los problemas sociales en sus países obligará a las élites de los diversos estados a implantar sistemas de planificación dirigistas mucho más amplios que los de los países industriales. Los procesos de este tipo sólo se podrán reconciliar parcialmente con la actual integración de América Latina en el mercado mundial. De todos modos muchos de los productos que América Latina pretende vender a los países industriales tienen que superar barreras arancelarias y otros obstáculos comerciales. Así que la única solución de los problemas de desarrollo de muchos países latinoamericanos, es la creciente extensión del mercado interno. Tal cambio no solamente repercutirá en las estructuras sociales y de productos en los diversos países, sino empeorará también sus relaciones con las naciones industriales en forma extraordinaria. Porque un desarrollo orientado hacia el mercado interno, habrá de obedecer leyes distintas a las de la industrialización dependiente que ha dominado en América Latina hasta la fecha. Uno de los objetivos esenciales del desarrollo orientado hacia el mercado interno, es la satisfacción de las necesidades fundamentales de la población. Objetivo que sólo puede alcanzarse mediante el cambio de los vigentes patrones de distribución del ingreso.

Justamente bajo este aspecto, sin embargo, resultaría sumamente difícil que los países latinoamexicanos más desarrollados buscaran la solución de sus problemas económicos en la mayor integración en el mercado mundial. En lo esencial esto afirmaría el status quo -la extrema desigualdad económica- y excluiría a las grandes masas populares del llamado "progreso económico", lo que a la larga no puede interesar ni a las élites dominantes, en vista de la estabilidad política. 


\section{Los sistemas politicos.}

El desarrollo político de América Latina ha vuelto a subir al primer plano debido a la política de derechos humanos de la administración. Garter. Los intentos de las élites latinoamericanas en el sentido de mantener su status quo social en la marcha del progreso económico y evitar pérdidas de poder político, han producido frecuentes errores políticos graves. Todos los sistemas políticos de América Latina -tanto los dictatoriales como los autoritarios, los populistas, los reformistas y los progresistas- han intentado con frecuencia "producir estabilidad" con el fin de crear las condiciones para el "progreso económico". Pero justamente el afán de estabilidad política a cualquier precio en sociedades de transición tales como se manifiestan en todos los países latinoamericanos en fases diferentes, necesariamente tiene que desembocar en repetidas revueltas que no pueden ser oprimidas a largo plazo, ni por las más duras dictaduras.

De manera que también - las actuales dictaduras de desarrollo primordialmente militares, sólo pueden ofrecer estabilidad por tiempo limitado. Hasta la fecha ninguno de los regimenes autoritarios ha podido asegurar el crecimiento económico y al mismo tiempo propulsar la integración social. El reconocimiento de este hecho y los impulsos originados de la administración Carter, han hecho que últimamente se haya creído oportuno volver a celebrar elecciones. Al. gunos militares parecen haber capitulado ante los problemas de gobernar sus países y dispuestos a regresar a sus cuarteles antes de que su propia institución se corrompa y divida totalmente a causa del desgaste en el ejercicio del poder.

Hasta los más represivos regímenes militares que se han creado. con asistencia la pacto norteamericano, su propia filosofía de estadocon la "doctrina de la seguridad nacional", no parecen aptos para afianzarse en el poder en forma permanente. Aunque ellos crean. haber desarrollado un sistema sui géneris que se diferencia tanto de las democracias liberal-parlamentarias occidentales como de las democracias populares totalitarias del Este, su "democracia" autoritaria tampoco constituye una solución viable de los problemas de sus países. En la mayoría de los estados de la región, los períodos políticamente estables yr las fases turbulentas se siguen unos a otros. Parece constituir un elemento de la cultura política de América Latina, el que los períodos de gobiernos civiles y militares se sigan. 
unos a otros como ondas, sin que alguno logre solucionar los centrales problemas políticos y sociales de sus respectivos países.

La progresiva "militarización de los tecnócratas" y "tecnocratización de los militares" en América Latina podría producir una nueva clase-pilote del sistema tan falta de legitimación popular como los regímenes militares tipo "seguridad nacional". Las elecciones y los partidos políticos tienen un gran peso hacia afuera, como legitimación frente a los países industriales occidentales de los que estos estados dependen en gran medida, pero es reducido su peso hacia adentro, a causa de las extremas discrepancias sociales. Dondequiera que llegue al poder un gobiemo legitimado por elecciones, la experiencia nos demuestra que frecuentemente no tiene otro destino que el fracaso debido a las presiones económicas y al poder de los grupo de veto internos y externos que siempre han sabido evitar cambios fundamentales de las estructuras económicas y sociales.

La esperanza frecuentemente expresada que el crecimiento económico y la modernización fortalecerían la estabilidad de los sistemas políticos latinoamericanos, mientras tanto ha sido refutada totalmente y con derrames de sangre en algunos países. Sigue cuestionable también la capacidad de desarrollo de las dictaduras militares, después de las experiencias hechas en los casos del Perú y Brasil. Es por lo tanto más probable, que la política latinoamericana se caracterizará en el futuro por modelos de dominación como los regímenes monopartidistas o los sistemas corporativos. Como no es posible reconciliar la participación de las bases con los modelos de dominación de estos tipos, la soberanía del estado seguirá gozando prioridad sobre la libertad individual en todas partes de América Latina.

\section{LOS POLOS DE DESARROLLO REGTONALES}

En los últimos años se han formado en América Latina centros de poder regionales. Sus bases son la relativa estabilidad política, una cierta potencia económica y el amplio reconocimiento internacional de los países en cuestión. Es además importante o quizá decisiva la capacidad de estos países para importar suficiente capital externo y tecnologia para poder realizar o financiar su progreso industrial.

México y Brasil constituyen hoy en día polos de desarrollo de primer orden, aunque por razones distintas. Los dos países sin embargo, se caracterizan por numerosas poblaciones rápidamente crecientes, territorios nacionales extensos y extraordinarias riquezas de 
materias primas. Venezuela y - con ciertas limitaciones- Argentina constituyen polos de desarrollo de segundo orden. Los - dos han alcanzado un alto grado de desarrollo, un elevado ingreso per cápita y poseen vastos recursos. Como país petrolero, Venezuela ha obtenido un peso político desproporcionado en la región, en relación a su potencial económico y demográfico, debido a su importancia estratégica para el abastecimiento energético de EE. UU. Argentina en cambio, que anteriormente era uno de los primeros países de América Latina, ha perdido en importancia dentro de la región, sobre todo a causa de su desarrollo político interno. El papel de Cuba que reune por lo menos, algunas características de un polo de desarrollo, no puede ser considerado aquí porque sus perspectivas de desarrollo son distintas, debido a su integración en el campo socialista. Por otro lado, no se debe subestimar su importancia respecto de algunos estados del Garibe al menos. Por último y a diferencia de los demás polos de desarrollo de América Latina, Guba ha logrado superar el subdesarrollo propio más elemental.

En el curso de los últimios diez años los países más pequeños y económicamente débiles situados en las zonas de los polos de desarrollo se han visto reducidos a posiciones satélites. Tanto Argentina como Brasil y también México y Venezuela han intentado sin embargo, que este hecho no se haga demasiado evidente, por razones políticas. En la formación de los polos de desarrollo ha jugado un papel decisivo, la distinción entre la expansión económica y la política. De modo que estos centros de poder regionales ejercen influencia económica, pero ningún control político en sus respectivas zonas. Para México, ésta es contituida por Centroamérica y una parte del Caribe; para Venezuela, el Caribe y en cierta medida, la región norte-andina; para Argentina, sobre todo los países de la cuenca del La Plata y para Brasil, casi todos los estados de Sudamérica, con la excepción de Argentina y.Venezuela.

Son caracerísticas típicas de un polo de desarrollo, las capacidades de sus élites dominantes para:

- Invertir en sus respectivas zonas, capital y tecnología en base a sus condiciones naturales y sus relaciones internacionales;

- Coordinar los potenciales de producción y de materias primas en sus respectivas zonas; 
- Eliminar parcialmente o colaborar con los intereses externos ya establecidos;

- Hacer atractivo el sistema económico y político propio, para las élites en sus respectivas zonas.

La dinámica propia de los polos de desarrollo produce una reestructuración de las zonas de influencia en América Latina que es combatida por muchos de los estados afectados relativamente pequeños. Al mismo tiempo, sin embargo, este proceso ofrece oportunidades económicas adicionales a naciones como Bolivia, Paraguay y Uruguay que no pueden ser igualados por los resultados de los intentos de integración formal. De manera que los países latinoamericanos están dispuestos en cierta medida a cooperar económicamente con los polos de desarrollo, a pesar de su marcada conciencia de soberanía nacional.

Los polos de desarrollo compiten económica y políticamente y sus papeles de lícleres no son de ninguna manera indiscutidos, según el grado de su estabilidad interna, su potencia económica y su reconocimiento internacional. Esto se refiere en menor escala a México y Brasil, sino mucho más a sus competidores en las zonas de influencia por ellos reclamadas: Venezuela y Argentina. En este contexto también son de cierta importancia los problemas de rivalidad política, aunque estos ríltimos pasan a un plano secundario con respecto a las oportunidades de ejercer influencia económica. Como consecuencia, Venezuela perderá influencia en el caso de reducirse sus ingresos petroleros, al igual de lo ocurrido con Argentina a causa de su permanente inestabilidad interna.

Al analizar el futuro desarrollo de estos centros de poder predominantemente económico en América Latina, se debe por lo tanto considerar también, la estabilidad del sistema y la cultura política de Ios diversos polos de desarrollo. No se puede tampoco excluir que hasta México y Brasil tendrían que reducir sus posiciones aunque no las pierdan por, completo, en el caso de producirse a mediano plazo, una disminución del poder de sus élites dominantes y,/o inestabilidades de sus sistemas políticos. Por otra parte, Argentina por ejemplo, podría reconquistar ya para los años ochenta su indiscutida posición como polo de desarrollo, a causa de sus condiciones sociales y económicas, sobre todo en el caso de un descenso brasileño similar al argentino entre. los años 1966 y 1976.

Estos factores de cambio más o menos internos son complemen- 
tados por tres factores externos como mínimo, que podrían limitar la posición de los actuales polos de desarrollo independientemente del reconocimiento internacional que de todos modos es decisivo. Estos factores son:

- El elemento politico-ideológico que podría provocar una disminución sustancial de la atractividad de los polos de desarrollo México y Venezuela, a causa del rol cubano en la zona centroamericana y del Caribe;

- El elemento militar y de seguridad que provocaría una sensible mengua del paso de Brasil y Argentina en el caso de un potencial conflicto bélico entre Perú, Bolivia y Chile;

- El elemento económico mundial que podría peligrar las actuales posiciones de los polos de desarrollo en América Latina en relativamente poco tiempo, a raíz de cambios esenciales de las estructuras de productos y mercados sobre todo en el sector energético.

Esto significa que ya una mera estimación aproximada de las perspectivas de los polos de desarrollo de América Latina, debe considerar en todo caso los siguientes factores:

- Los factores internos, incluyendo la estabilidad del sistema, el crecimiento demográfico, los recursos naturales y las perspectivas económicas;

- Los factores intrarregionales, en otras palabras, el peso específico de cada polo de desarrollo dentro de su respectiva zona de influencia y la probabilidad de una disminución o un incremento del mismo, a causa del desarrollo de otros estados;

- Los factores interamericanos que siguen teniendo alta prioridad en el análisis de cualquier proceso latinoamericano, a pesar de las reseryas de EE. uU. que pueden observarse últimamente y que son de importancia decesiva particularmente en el caso de México, como país vecino de $\mathrm{EE}$. UU.;

- Los factores extrarregionales que en vistas de la creciente emancipación de la política exterior de Brasil y también de México, determinarán la posición de los polos de desarrollo en la economía mundial $y$ en el sistema internacional en general. 


\section{México.}

Desde la consolidación de su revolución por las reformas económicas del año 1940, México ha pasado por un período de extraordinaria estabilidad, en términos latinoamericanos, que ha fortalecido su posición como polo de desarrollo al norte de América Latina. Las señales de crisis de los últimos años que crearon dudas acerca de la continuidad de esta estabilidad, aunque no se han eliminado, por Jo menos han sido cubiertos por la nueva posición de México como uno de los más importantes países exportadores de petróleo en el futuro. Otra ventaja de México es su identidad nacional que se remonta a la revolución de 1910 a 1917 y que ha sido profundizada en la historia más reciente. La permanente necesidad de tener que afirmarse frente a los demasiados poderosos vecinos del norte, ha convertido a Mcxico en una nación cuyo amplio y variado potencial quizás se ponga de manifiesto sólo a finales de este siglo.

Son diversas las razones por las cuales el sistema político de México ha podido mantener su extraordinaria estabilidad por más de medio siglo. EI régimen monopartidista de facto ha logrado la transición de la sociedad agraria a la industrial provocando relativamente pocos conflictos de adaptación. Este sistema que no es comparable con una democracia del estilo anglosajon, ha venido desarrollando estructuras y leyes muy sui géneris que se han mantenido constantes por varias generaciones y que permiten al Presidente en ejercicio, sólo una "dictadura temporal". En este sistema político bastante progresista, en términos latinoamericanos, la alta capacidad organizativa del partido oficial PRI (Partido Revolucionario Institucional) permite dirimir todos Ios conflictos en el seno del partido, con lo que queda canalizada, si bien no eliminada, la formación de antiélites.

El elevadísimo crecimiento demográfico de más del $3 \%$ anual, sin embargo, pone en peligro la actual estabilidad del país, a mediano plazo. La brecha entre aquellos que están integrados en el sistema social y económico existente y los estratos marginales que el sistemá ya no es capaz de absorber, se está ensanchando constantemente. A pesar de la increíble riqueza del país es probable que se produzcan más y mayores disturbios sociales en los próximos años, a no sè que se introduzcan nuevos patrones distributivos. Los problemas financieros del país no son tan graves como pareciera señalarlo el elevado endeudamiento externo. Al contrario: México tiẹne muy buenas perspectivas de extraordinarias tasas de crecimiento económico a me- 
diano plazo, debido a sus reservas petroleras. En este contexto hay que tener en mente, sin embargo, que los ingresos petroleros frecuentemente no son beneficiosos para el desarrollo social integral, como lo demuestra el ejemplo de Venezuela.

La vecindad de EE.UU. seguirá ofreciendo oportunidades de mercado para los productos del país, a pesar de la desfiguración de la estructura económica mexicana causada por esto. En resumen: si se logra mantener la estabilidad del sistema político mediante adaptaciones a las condiciones de los años ochenta, los factores incluso harán crecer la atractividad del polo de desarrollo de México a mediano plano, no por último debido a la creciente liberalidad política.

El creciente peso de México dentro de su subregión se manifiesta también, entre otras cosas, en el hecho de que los centroamericanos lo vean como el "coloso del Norte", más que a los propios EE.UU., aunque México no ha intentado nunca imponer su predominio sobre sus vecinos menores al Sur. Como es de prever que la región centroamericana se caracterizará, en los próximos años, por una gran inestabilidad, la influencia de México aumentará sustancialmente; tanto más así porque EE.Uu. -como quedó demostrado en las experiencias recientes de Nicaragua- tienden a defender sus intereses en Centroamérica, en una forma menos pronunciada que en el pasado.

El rol de México en el Caribe, si bien no reviste la importancia de Centro Ámérica, acusa un peso francamente creciente, jugando un papel central sus relaciones con Jamaica y Guba. Sus relaciones con Cuba son de especial trascendencia porque México se había firme: mente negado, ya en 1962 y como único país latinoamericano, a suspender las relaciones diplomáticas con este país caribeño. Tal firmeza frente a las presiones estadounidenses ha sido beneficiosa para México a largo plazo, aunque ella no fue exclusivamente un producto de simpatía por la Guba de Gastro.

Fueron otros dos factores que han jugado un papel decisivo en este contexto: el interés específico de México en otras revoluciones y su firme defensa del principio de la no intervención que hubiera sido lesionado por la suspensión de sus relaciones con un país como Cuba.

México además logró interesar en parte, mediante relaciones amistosas; al otro polo de desarrollo en el área centroamericana y del Garibe -Venezuela- por sus propios fines, aunque la ve como posible competidor. La creación del Sistema Económico Latinoamericano (SELA) es un producto de sus polfticas comunes. A pesar de ello 
podrían producirse tensiones en el futuro, sobre todo en la política de exportación de petróleo.

En lo que respecta a Sudamérica, México ha empezado a jugar un papel importante sólo en los años setenta. El respaldo del Gobierno de Allende en Chile, por ejemplo, fue pieza clave de la política latinoamericana del Presidente Echeverría. Se originaba, igual que los otros contactos dentro de la región, en el deseo de ocupar una posición de liderazgo tercermundista. Consecuencia de la creciente militarización de los sistemas de dominación sudamericanos, el prestigio de México como estado relativamente democrático crecî́ó en una gran parte de las élites democráticas de la región.

A pesar de las evidentes tensiones en su relación con el aplastante vecino EE. UU., México se esforzará a largo plazo y conscientemente, a ocupar una función de puente entre EE. UU. y América Latina. A mediano plazo esto le proporciona una excelente base de partida como polo de desarrollo en Centroamérica y el Caribe que será aún mejorada por la incipiente oportunidad de prestar ayudas bilaterales.

Su situación geográfica como país vecino de EE. UU. significa para México al mismo tiempo bendición y maldición de su desarrollo. La evidente brecha económica entre los dos estados ha producido deformaciones de la estructura económica mexicana, así como masivas emigraciones de mano de obra y un "drenaje de cerebros" de los especialistas. Por otro lado, el choque entre el Tercer y el Primer Mundo ha impulsado a México hacia extraordinarios esfuerzos de desarrollo. Ya que casi dos terceras partes de su comercio exterior se realizan con EE. UU., México será capaz de seguir manteniendo su extraordinaria posición económica, aunque tendrá que continuar soportando las desventajas entrañadas en tal dependencia de EE. UU. Sobre todo los acontecimientos más recientes en el sector energético contribuirán enormemente a mejorar la posición negociadora de México.

En la reorientación de la relación bilateral el estilo diplomático del intercambio entre México y Ex. uU. seguirá más bien el ejemplo de Venezuela, sin que se produzcan verdaderas imposiciones de:los precios petroleros como en el caso de los países árabes. Porque México no puede dejar de considerar los intereses por materias primas de la vecina super potencia y ya por esta razón la será difícil afiliarse a la opEP. Por otra parte, su credibilidad nacional como país de avanzada en el Tercer Mundo dependerá en gran medida de que no se sujete 
demasiado a los intereses estadounidenses, sino que haga valer su potencia económica frente al poderoso vecino.

Su situación geográfica de todas maneras seguirá siendo un factor dominante de su papel como polo de desarrollo, porque EE. UU. puede ejercer influencia sobre los márgenes de actuación interna y externa de México. La ventaja de esta vecina "dominación ajena" es que EE. UU. siempre apoyarán a sus vecinos mexicanos más gustosamente que a otros países latinoamericanos, independientemente de las dificultades económicas y políticas.

A pesar de sus limitadas posibilidades para diversificar sus relaciones políticas y económicas internacionales, México ha hecho extraordinariós esfuerzos en esta dirección en los últimos años. Los acuerdos comerciales con la Comunidad Europea y el Consejo de Asistencia Mutua de Europa oriental de 1975 y su papel de líder en la elaboración y aprobación de la "Carta sobre los Derechos y Deberes Econó. micos de los Estados" de 1974, constituren los ejemplos más resaltantes de ello. Esta política, sin embargo, no ha tenido más que efectos marginales, sobre el desarrollo económico de México mismo.

Los intentos mexicanos de diversificar sus relaciones externas dan fe de su deseo de desarrollar marcadas ideas de distanciamiento de su poderoso vecino y las concepciones económicas de éste. Las recientes negociaciones entre las administraciones López Portillo y Carter han evidenciado este deseo nuevamente.

A nivel del sistema internacional, México se siente una "potencia anti-status quo" y defensor de un nuevo orden económico internacional. Con lo que México logrará afianzar en forma duradera su posición dentro del Tercer Mundo. Por eso México tendrá una función importante en todas las futuras negociaciones entre los países industriales y los subdesarrollados. $Y$ en este contexto, tanto los factores interamericanos por su estrecha relación con EE. UU., como también los factores extrarregionales por su perfil tercermundista, le ofrecen a México perspectivas particularmente favorables como polo de desarrollo.

\section{Brasil.}

La vía brasileña a partir de Ia así llamada revolución de 1964, ha sido observada en muchas partes del mundo con admiración en lo que respecta a sus tasas de crecimiento económico y al mismo tiempo, con repudio en lo que respecta a la represión ejercida por el sistema 
de gobierno. Como potencia líder a nivel regional latinoamericano, Brasil ha sabido hacer efectiva su política, al menos en forma indirecta, en una gran parte del continente. Simultáneamente ha hecho valer su influencia mucho más allá de la región, debido a sư tamaño y su habilidad diplomática.

Preguntar por la estabilidad del modelo brasileño significa sobre todo, preguntar por sus éxitos. Mientras que la alianza entre militares y tecnócratas era capaz de producir. éxitos económicos, sobre todo para los estratos superiores de la sociedad, este modelo era estable. El sistema disponía de una capacidad organizativa y un poder político que sólo en períodos de crisis se suele conceder a los gobiernos de las naciones industriales occidentales. De manera que podía imponer sus proyectos políticos en forma cași independiente de los grupos de interés y de la aprobación de las bases.

El consenso entre militares y élites económicas quedó roto, como lo demuestran los acontecimientos acaecidos después de 1974, en el momento en que se terminó el éxito económico. La estabilidad de este modelo de desarrollo militar-tecnócrata se ve en peligro conforme la coyuntura internacional y los desenvolvimientos internos obligan a Brasil a introducir cambios de la política económica. La transición del régimen militar hacia gobiernos civiles previsibles para los años ochenta, seguramente contribuirá a acentuar aún más la desestabilización de Brasil como polo de desarrollo en su conjunto. Puesto que el consenso vigente hasta en la actualidad fue logrado en base a grandes sacrificios políticos $y$, no por último, al terror dirigido desde arriba, es natural que la paulatina apertura del sistema hace inevitables ciertas inestabilidades a mediano plazo. Todos los anuncios de los militares en el sentido de la democratización fundamental del sistema en un futuro no muy lejano deben por lo tanto verse con escepticismo, porque ella peligraría la "estabilidad militar" lograda a tan elevados costos sociales. Bajo el régimen militar, los problemas realmente críticos no se han acercado a soluciones en lo más mínimo, por lo cual es de esperar que sólo podrán convertirse en grandes temas del debate político, después de una mayor apertura del sistema. Los principales temas serán la deuda externa y las inversiones extranjeras, como signos más visibles de la dependencia externa, así como la participación política.

Debido a la problemática situación del sector energético, se ha intentado adaptar el modelo brasileño a las nuevas condiciones, ya desde el tiempo de la crisis petrolera. Los brasileños evidentemente 
ven una oportunidad en la transformación del modelo de crecimiento orientado hacia las exportaciones, a un modelo de mercado interno, incluyéndose en este último, a largo plazo, toda el área de influencia de Brasil como polo de desarrollo. Una política de este tipo requerirá, sin embargo, de profundos cambios estructurales de la economía y la sociedad brasileñas. Los militares no se han puesto de acuerdo todavía si el desarrollo debe seguir consecuentemente orientado hacia este objetivo, o si se puede esperar una mayor integración a la economía mundial bajo las expectativas de precios crécientes de las materias primas y de disminución de las tarifas arancelarias.

El vasto territorio de Brasil con sus 115 millones de habitantes hace parecer muy prometedor un modelo de mercado interno extendido a los países vecinos. Salvo una fase de transición indudablemente problemática para los años ochenta, este modelo correspondería mucho a las marcadas ideas autonomistas de Brasil. A mediano plazo, sin émbargo', la rápida transformación de un país subdesarrollado a una "gran potencia" sin simultáneos cambios de las estructuras políticas y sociales, comprometerá en elevado grado de estabilidad interna de Brasil como polo de desarrollo.

En los años setenta Brasil se ha establecido como potencia regional a nivel sudaméricano, en un grado nunca alcanzado ni por Argentina en los momentos de su máxima influencia. Brasil presta una cuantiosa asistencia al desarrollo dentro de la región y ha ayudado particularmente a los regímenes ideologicamente afines en la consolidación de su poder y la imposición de sus políticas de seguridad interna. Sin embargo, Brasil también supo disipar, por lo menos temporalmente, los temores ante una hegemonía brasileña que surgieron periódicamente. En los últimos tiempos incluso ha logrado mejorar sus relaciones con Argentina, su tradicional rival en el liderazgo de Sudamérica.

En ciertos aspectos los brasileños se creyeron capaces de poder repetir, en forma postergada, fases de desarrollo similares a las históricamente transcurridas por EE. UU. En la conquista de su propio hinterland, como igualmente respecto a su influencia sobre otros países, Brasil había esperado poder repetir el ejemplo de EE. UU. en su ascenso a la posición de potencia mundial. Esta fue una de las razones por las cuales la estrecha alianza con EE. UU. históricamente siempre ha sido una preocupacion prioritaria de la política exterior brasileña. Sólo a principios de los años setenta, cuando Brasil empezó a. ver en EE. Uu. un obstáculo más que una ayuda para su ascenso 
dentro del sistema internacional, EE. Uu. se convirtió en un socio externo entre otros.

En los últimos diez años los brasileños hain basado sus relaciones bilaterales en cuatro criterios fundamentalmente, que corresponden a sus requerimientos de desarrollo. Según ellos, un socio exterior debe ofrecer las siguientes oportunidades:

- Acceso a un mercado amplio y diversificado;

- Acceso a materias primas, particularmente a fuentes energéticas;

- Acceso a fuentes finacieras;

- Acceso a tecnología moderna.

Mientras que los Ex. UU. estaban dispuestos a cumplir con la mayor parte de estos criterios, eran el socio privilegiado por lo menos bajo los puntos de rista del comercio exterior.

Sin embargo, se puso de relieve que también algunos otros países son capaces de ofrecer similares oportunidades a Brasil, sin atarlas a exigencias respecto a la política exterior. Durante un tiempo los norteamericanos habian intentado limitar las ambiciones internacionales de Brasil al área latinoamericana, interpretando muy equivocadamente los objetivos internacionales mundiales de los militares brasileños. Se sentian más bien molestos ser vistos como socio menor o gendarme de $\mathrm{Ex}$. UU. en América Latina. Por ello aprovecharon cualquier oportunidad para solidarizarse contra EE. UU. con otros regimenes militares autoritario latinoamericanos. De modo que la revacación a muy corto plazo, de la larga cooperación militar con EE. UU. pone de manifiesto la disposición a seguir políticas independientes al menos en algunos sectores, incluso en contra de la voluntad de EE. UU.

Habría sido imposible asumir esta actitud independiente que Brasil viene demostrando últimamente, si no hubiese logrado en los años recién pasados -a pesar de su continuada dependencia económica de EE. UU.- establecer una posición respetable en el sistema internacional y en la economía mundial, mediante políticas muy hábiles de relaciones externas en lo político y comercial. Además de las relaciones 
económicas con EE. UU. que siguen teniendo extraodinaria importancia, Brasil se apoya hoy en día, con prioridades distintas en los siguientes socios internacionales:

- Europa Occidental, particularmente la República Federal de Alemania;

- Asia Oriental, particularmente Japón;

- E1 Tercer Mundo, particularmente Africa Negra;

- Los países socialistas, particularmente la Unión Soviética.

En su intento de conseguir máximas ventajas para su propio desarrollo, Brasil ha sabido llevarse muy bien y durante años, hasta con países políticamente contrarios. El volumen de su comercio exterior con los países socialistas, por ejemplo, creció en una medida descomunal para un país latinoamericano, aunque no alcanzó las tasas espectaculares de su intercambio con Europa Occidental. Además Brasil lograba mantener buenas relaciones, durante mucho tiempo, tanto con Israel como con los países árabes, asi como con Africa Negra igual que con Sudáfrica. Los brasileños aprovecharon la disolución del imperio colonial portugués para acordarse de la herencia histórica común y para comprometerse económica y culturalmente con Angola y Mozambique. Su hábil diplomacia ha permitido que Brasil ocupara el papel de uno de los más importantes mediadores entre los intereses de los países industriales y los subdeșarrollados, dưroș en lo material y flexibles en lo formal.

Los acontecimientos más recientes señalan que Brasil podrá alcanzar su anhelada posición de gran potencia, más bien mediante el rol de líder tercermundista que mediante su integración en el Primer Mundo. Porque si bien son muy estrechos los vínculos idealógicos entre Brasil o sus élites dominantes y el mundo occidental, mucho menos lo es su afinidad estructural con los países industriales. Su futuro desarrollo interno deberá tomar esto en cuenta. Las decisiones incipientes en los próximos años no peligrarán la posición brasileña como polo de desarrollo, pero disminuirán su atractividad para los países recinos debido a la inestabilidad interna que es de esperar. 


\section{Venezuela.}

Venezuela ocupa un rol especial al lado de los dos polos de desarrollo de primer orden, porque siendo un país pequeño con solamente 13 millones de habitantes ha logrado alcanzar una posición internacional que sobrepasa los límites de la región. Esto se debe a que Venezuela fue hasta hace poco tiempo, el país de mayor riqueza petrolera de América Latina y que en una región dominada por regímenes militares, ha sido una democracia ejemplar por más de veinte años.

El hecho que un pequeño país con posibilidades relativamente reducidas desempeñe un papel fuera de orden en América Latina, no es de por sí nuevo como lo demuestra el ejemplo de Cuba. En ciertos aspectos el desarrollo cubano en las dos últimas décadas es comparable con el de Venezuela en el sentido de que ambos países, partiendo de premisas relativamente similares, han seguido vías políticamente muy distintas que se han manifestado sin embargo, como vías muy exitosas hacia la política internacional.

Es cierto que los factores internos han sido favorables para Venezuela. El país ha gozado de una notable estabilidad democrática después de 1958; los gobiernos han tenido la amplia legitimación popular y se ha desarrollado un sistema bipartidista relativamente estable. El petróleo creó las condiciones para este desarrollo extraordinario en términos latinoamericanos. Estos gobiernos democráticos no han podido resolver, sin embargo, a pesar de elevados ingresos petroleros y de una no muy numerosa población, los problemas económicos y sociales más apremiantes. En cambio, los elevados ingresos externos le han permitido al país financiar una democracia, sin tener que recurrir a una redistribución a costa de los estratos superiores. De modo que la maliciosa palabra de la "democracia del buen tiempo" se ajústa también a Venezuela. Los líderes democráticos del país están conscientes de que la estabilidad de la democracia depende de su éxito en diversificar la economía y crear numerosos nuevos empleos en la próxima década. Sólo de esta manera podrá enfrentar Venezuela crisis económicas y sociales causadas por la paulatina reducción de la producción petrolera.

En Venezuela fue más fácil que en otros países latinoamericanos, establecer un consenso nacional porque el mismo podía ser financiado mediante cuantiosos pagos de los fondos públicos. Es por otro lado posible que la estabilidad política no sea afectada en una fase 
de transición económica y que Venezuela siga siendo atractiva para otros países de la región.

Bajo la presidencia de Carlos Andrés Pérez, Venezuela se ha esforzado sobremanera por lograr la solidaridad de los países latinoamericanos. Son pruebas evidentes de ello, la asistencia financiera a países menores de la región, el importante papel venezolano dentro del Pacto Andino y la creación, junto con México, del Sistema Económico Latinoamericano (SELA). Su posición de cierto liderazgo en el Caribe cuyos mini-estados independientes crecientes en número buscan el apoyo económico de Venezuela, no es tan fácilmente aceptada por las islas mayores, como lo demuestran por ejemplo, los conflictos con Trinidad-Tobago. Por otro lado el área de influencia de Venezuela como polo de desarrollo, no se limita únicamente al Caribe. Venezuela también ha realizado muchas actividades en Centroamérica y la región andina. Sorprendentemente esto no ha producido conflictos con la potencia decisiva en la región de los EE. UU. También sus relaciones con México han sido buenas y hasta amistosas, aunque existe cierta competencia de dos polos de desarrollo acerca de sus respectivas áreas geopolíticas.

Las relaciones con EE. UU. siempre han sido de vital importancia para Venezuela. A partir de la crisis energética de 1973-74 también los EE. UU. se dieron cuenta de la importancia estratégica de Venezuela de la que proviene nada menos que una cuarta parte de sus importaciones petroleras. A partir de la misma fecha Venezuela también pudo incrementar su poder de negociación, debido a su afiliación a la opep. Fue un buen ejemplo de esto la nacionalización de las empresas petroleras extranjeras. Este poder de negociación podría reducirse sin embargo, ya para mitades de la década de los ochenta, a causa de las enormes reservas y posibles exportaciones petroleras mexicanas. Por el momento al menos, parece improbable que EE. UU., pueda servirse de Venezuela contra México o viceversa. Más bien parece que los venezolanos están transmitiendo a México, sus experiencias en el tratamiento de este gran comprador de petróleo.

A pesar de todo no es tan clara la actitud crítica de Venezuela frente a EE. UU. como podría sugerirlo el papel de portavoz que asumió temporalmente para el área hispanoparlante. Es cierto que los venezonalos repetidamente advirtieron a $\mathrm{EE}$. UU, que no pueden seguir tomando decisiones referentes a la región en forma unilateral, como lo demuestran las cuestiones del restablecimiento de relaciones diplomáticas con Cuba, del Canal de Panamá y la crisis nicaragüense. Por 
otra parte, los vínculos sistémicos entre eE. vU. iv la Venezuela dependiente de ellos son tan profundos que el aprovechamiento de su campo libre en la política internacional no constituye tanto una vía propia, sino más bien el intento de compensar la invariada posición dominante de EE. UU.

Con frecuencia es pasado por alto el hecho que Venezuela como miembro fundador de la 'OPEP ha jugado un papel sobresaliente, no solamente en el conflicto Norte-Sur, sino también en la elaboración de las estrategias tercermundistas en general. Ha enriquecido la discusión sobre un nuevo orden económico internacional con sus experiencias acumuladas en muchos años de enfrentamiento con las empresas transnacionales más grandes, las petroleras. Justamente debido a su gran dependencia de EE. UU. es tan marcada su sensibilidad trente a los problemas que acompañan tal dependencia. Esta experiencia también la une con México. En lo que a la 'opep se refiere, Venexuela se ve más bien en un rol de mediador: es cierto que está interesada en altos precios para su petróleo, pero contrario a los países árabes no está dispuesta a ejercer presiones políticas sobre EE. UU. porque no considera el petróleo como arma política para la solución de problemas regionales.

Otro criterio importante del rol venezolano como polo de desarrollo es que los partidos socialdemócratas y demócratacristianos lie América Latina la ven como centro democrático de la región, debido a su estabilidad democrática. En consecuencia de esto las relaciones internacionales a nivel de partidos políticos con otros países latinoamericanos son mantenidas en gran parte vía Venezuela. Esta forma de ejercer influencia civil sobre las élites en las salas de espera, constituye otro factor positivo para la posición de Venezuela como polo de desarrollo en América Latina.

Los tres polos de desarrollo decisivos en América Latina - México, Brasil y Venezuela - han alcanzado sus posiciones primordialmente debido a su potencia económica. Pero también sus muy diferentes estructuras internas y la respectiva forma de estabilidad política relacionada con ellas, sirven de ejemplo a grupos sociales divergentes en todos los países latinoamericanos, para su propio desarrollo nacional: Ios políticos democráticos se orientan en Venezuela, los defensores del sistema monopartidista en México y los abogados de la "política de seguridad nacional", en Brasil. 


\section{Argentina:}

Resuita difícil decidir si Argentina -durante mucho tiempo el país lícler en América Latina- debe sumarse a los polos de desarrollo de la región, por meras consideraciones históricas o en cambio, en base a la expectativa de un nuevo ascenso. Existen pocos países en América Latina que pudieron alcanzar una posición similar a la de Argentina. Hasta hoy en día Argentina sigue siendo el país más rico de América Latina en términos relativos, debido a su reducida población de sólo 26 millones, así como a sus recursos naturales y su desarrollo social en general. La riqueza de Argentina no se limita a su situación de autarquía en casi todos los renglones básicos incluyendo el petróleo, sino se debe también a su sistema educativo, su infraestructura y a muchos otros factores constitutivos de un estado moderno, que son los más desarrollados de toda la región. Al final de la Segunda Guerra Mundial, Argentina ocupaba todavía el sexto lugar entre los países más ricos del mundo, que por su afiliación indirecta al Imperio Británico se sentía casi más estrechamente vinculado con Canadá y Australia que con sus vecinos latinoamericanos.

En los últimos años, sin embargo, Argentina ha pasado por una etapa de un extraordinario descenso. Ningún otro país latinoamericano jamás fue sacudido por una permanente crisis política como la Argentina, que de hecho no fue interrumpida desde 1955. Situaciones similares a un estado de guerra civil entre 1974 y 1977 han llevado al pais al borde del caos cuyas consecuencias difícilmente serán superables en un período previsible.

El intento de Perón de integrar a la clase obrera en el sistema político del país, sin quitarle su posición a la clase alta tuvo ciertos éxitos en los tiempos de abundancia de fondos, es decir, en los primeros años de postguerra, pero fue imposible repetirlo en 1973. Por otra parte, ninguno de los gobiernos civiles o militares entre 1955 y 1973 logró gobernar sin la participación política de la clase obrera y no se vislumbra tampoco ningún tipo de consenso interno. La bien organizada clase obrera rechaza con uñas y dientes, a pesar de toda represión política, cualquier propósito de cargarla a ella sola con el descenso económico y los militares están reñidos entre ellos mismos respecto a la vía más prometedora para salir de la crisis permanente del país. No se proponen tampoco traspasar el sistema político a las manos de civiles en un futuro no muy lejano. Podemos pues constatar que Argentina seguramente no reune las condiciones de estabilidad 
interna que caracterizan a los otros tres polos de desarrollo en América Latina.

Por las mencionadas razones Argentina ha perdido mucho prestigio dentro de la región. La tradicional rivalidad con Brasil, manifestada en el pasado particularmente en la lucha por ejercer influencia en los estados tope como los son Bolivia, Paraguay iy Uruguay, se ha reducido últimamente porque Brasil sobrepasó a Argentina ya tiempo atrás, al menos en términos absolutos. Por otro lado Argentina sigue siendo un rival serio, debido a su desarrollo social en general y a su ingreso per cápita. Sobre todo en la batalla futura de fuentes energéticas no disminuirán sus disputas con Brasil, tanto respecto a los proyectos hidroeléctricos del Paraná, como respecto de la extensión del sector energético nuclear en ambos países. Son conflictos sobre recursos también, los que determinan la disputa con otro vecino, Ghile, ya que el diferendo aparentemente legalista sobre las tres pequeñas islas del Beagle, sólo resulta comprensible ante el trasfondo del posible aprovechamiento de la zona económica de las 200 millas en este sector.

Como polo de desarrollo Argentina parece carecer de atractividad hasta en el área regional más próxima. No obstante, sus vecinos la aceptan como cierto factor corrector internacional frente a las pretensiones expansionistas de Brasil. Después de una posible estabilización interna, sin embargo, Argentina podría volver a ser atractiva para toda la región porque ha sabido mantener su posición de liderazgo en lo tecnológico y cultural y seguirá siendo de esta manera, un punto de atracción para todos los países hispanoparlantes de la región.

También la tradicional actitud antiyanqui de Argentina, sólo temporalmente reducida bajo los regímenes militares, fortalece su debilitada posición como polo de desarrollo. Es cierto que siempre vio a EE. UU. como rival y nunca como socio en el hemisferio. A través de toda su historia Argentina se ha orientado más hacia Europa y fue competidor de EE. UU. en el mercado mundial, como exportador de alimentos. La actual crítica de Argentina iniciada por la administración Carter, con respecto a la permamente lesión de los derechos humanos y la suspensión por EE. UU. de los créditos y las exportaciones de armamentos en que ha desembocado, también llegó a molestar a los militares argentinos que anteriormente habian sido pronorteamericanos. En consecuencia de ello las relaciones entre eE. UU. y Argentina han descendido a su más bajo nivel desde la Segunda Guerra Mundial. Tampoco son buenas las perspectivas de su mejoramiento a mediano 
plazò, porque independientemente de la actual política de Cartex los argentinos no se inclinan a supeditarse a los intereses norteamericanos. Por otro lado Argentina tiene considerablemente menor importancia estratégica y económica para $\mathrm{EE}$. UU. que México, Brasil o hasta Venezuela, causa por la que tampoco harán grandes esfuerzos los norteamericanos, para acercarse a Argentina de alguna forma.

Esta carente componente interamericana se explica también por el hecho que Argentina -no por último debido al elevado número de inmigrantes europeos - siempre se ha sentido el más europeo de los países latinoamericanos.

También en sus relaciones comerciales, Europa ocupa un lugar dominante: la occidental, en las importaciones; la oriental, en las exportaciones ya que Argentina perdió sus mercados tradicionales debido a las políticas de la Comunidad Europea. En lo referente a ideología y política de seguridad, Argentina. ha buscado contactos cada vás más intensivos con Sudáfrica en los últimos años. A pesar de ello Argentina sigue siendo miembro del movimiento de los no alineados, como único de los cuatro polos de desarrollo de América Latina, aún cuando el régimen militar actual hace muy poco uso de este hecho. Esta posición internacional hace recordar la "Tercera Posición", de Perón, quien con bastante anterioridad a los esfuerzos emancipadores de los países subdesarrollados había buscado un tercer camino entre el capitalismo y el comunismo. Basándose en la situación geográfica de Argentina, Perón opinaba que un país como Argentina no debería ver el mundo desde la perspectiva del conflicto Este-Oeste.

No se puede excluir que un cambio de la polf́tica interna podría hacer nuevamente relevante una política argentina de una "Tercera Vía". Justamente por sus amplias experiencias internacionales, Argentina podría asumir una importante posición dentro del conflicto Norte-Sur y con ello también revalorizar su rol como polo de desarrollo, en la actualidad algo reducido.

III. DIEZ GONGLUSTONES SOBRE EL DESARROLLO DE AMERIGA LATINA EN LA DECADA DEL 80

1. En América Latina no se demostrará, en el futuro previsible, una tendencia política o económica común. Las diferencias demasiado grandes entre las situaciones económicas y sociales de los diversos países tampoco permiten formular objetivos comunes. Resultan, sin 
embargo, ciertas perspectivas acerca de las condiciones de desarrollo general.

2. Las sociedades de casi todos los países latinoamericanos se encuentran en un proceso de cambios rápidos. En consecuencia, la inestabilidad política será también en la próxima década, parte inevitable del desarrollo, a pesar de los modelos de dominación militares. En este proceso la democracia será vista como objetivo y no como proceso social.

3. El desarrollo económico continuará, en grados diversos dentro de la región, en la misma o en aún mayor medida que en la década pasada. Según todos los criterios este desarrollo no contribuirá, sin embargo, a una distribución más justa de la riqueza entre los diversos estratos sociales y por lo tanto, no promoverá el progreso social general dentro de la región y menos aún la satisfacción mínima de las necesidades de todos sus habitantes.

4. El nacionalismo transcurrirá, en los diferentes estados de América Latina, en otras fases virulentas. El actualmente predominante antiyanquismo se reducirá a consecuencia de un paulatino repliegue estadounidense en la región. En cambio aumentará la oposición frente a los nuevos polos de desarrollo regionales. La búsqueda de posiciones propias tomará formas extremas en muchas naciones, de modo que no se pueden excluir conflictos bélicos dentro de América Latina.

5. El rechazo de la planificación familiar por parte de la mayoría de los regimenes provocará una enorme explosión demográfica. Se da por segura la casi duplicación de los actuales 330 millones de habitantes de América Latina, a 600 millones para finales del siglo. El inmenso desempleo resultante de tal situación pondrá en extremo peligro los sistemas ya en la próxima década, inclusive en los casos de gobiernos relativamente exitosos.

6. Según indican las experiencias, frecuentemente se saltan etapas. de desarrollo en América Latina. Por otra parte, algunos estados de la región han entrado en fases de franco descenso debido a condiciones de la economía mundial o de sus propios sistemas. Uruguay, Chile y Argentina son ejemplos clásicos de esto para los años setenta. En la próxima década otras naciones tendrán que seguir, con bastante certeza, derroteros iguales. 
7. La industrialización de la región en la pasada década ha disminuido parcialmente, la incluencia directa de EE. UU. en la economía latinoamericana. La evidente diversificación del comercio exterior tuvo como consecuencia que los intereses de EE. vu. no han crecido en la misma escala como los de otras naciones industriales, por ejemplo, Alemania Federal y Japón. Este proceso se acentuará más aún en los próximos años, aunque los EE. UU. harán todo lo posible para evitar ser cortados de los importantes yacimientos de recursos naturales, los mercados para bienes industriales y las posibilidades de inversión en América Latina. La dependencia general latinoamericana de la importación de capital y tecnología de los países industriales no disminuirá, sino crecerá.

8. Por razones industriales América Latina, en la próxima década, se identificará en mayor grado con el Tercer Mundo que en la del 7.0. Este proceso sólo puede ser detenido mediante concesiones unilaterales por parte de los países industriales, frente a las expectativas económicas latinoamericanas; por el momento no hay todavía indicios para tal actitud.

9. Las relaciones entre América Latina y Europa podrían llegar a tener formas extraordinarias en el caso que Europa Occidental lograse librarse de la imagen de socio menor de EE. UU. Dada la oferta casi igual de capital, tecnología y acceso a mercados, América Latina siempre daría prioridad a Europa en proyectos de cooperación, no por último debido a las menores posibilidades de verse expuesta a presiones políticas. Esto cobraría aún más valor, si Europa en el futuro estuviese dispuesta a ofrecer su cooperación libre de exigencias dogmáticas y a renunciar a la exportación de sus modelos económicos y sociales.

10. El postulado por la redistribución de poder, influencia y bienestar no será planteado únicamente dentro de los estados latino. americanos. Se trata al mismo tiempo de un postulado de la región en su totalidad, frente al sistema político y económico internacional vigente. Este postulado será apoyado con vehemencia incluso por todos aquellos estados de América Latina que se oponen estrictamente a tal redistribución en sus propias sociedades. 